workers may develop occupational dermatoses. ${ }^{3}$ Most occupational contact irritants are alkalis, acids, soaps, detergents, organic solvents, reducing agents, oxidising agents, and physical factors such as friction; the common occupational contact allergens are chromate, synthetic adhesives and sealants, biocides, and a wide variety of low $(<1000)$ molecular weight organic chemicals. Such substances are met with as much in hairdressing and catering as in engineering and construction.

Occupational dermatitis is sometimes difficult to diagnose as accurately as its effective prevention demands, especially when allergens may be responsible. But much occupational dermatitis is due to irritants rather than to allergens and is preventable if we use the knowledge we already have. Quick, simple, and inexpensive preventive measures are still being needlessly ignored. This is the core message of the Health and Safety Executive campaign. Once well established, the prognosis of occupational dermatitis is surprisingly poor, ${ }^{4}$ and hence primary prevention is paramount. Individuals and companies who believe themselves free of skin problems may be storing them up for the future by their current work practices. The time to think about skin hazards is while they are still potential hazards and not to delay matters until dermatitis has already developed.

Information on many aspects of preventing occupational dermatitis is available by contacting local Employment Medical Advisory Services offices (listed under Health and Safety Executive in the telephone book) or from the Dermatitis Campaign Secretariat, Health and Safety Executive, Magdalen House, Trinity Road, Bootle L20 3QZ (051 951 9545). The National Eczema Society also provides useful information about eczema at work (Tavistock House North, Tavistock Square, London WC1H 9SR (01 388 4097)). Doctors and others may find themselves being asked for help in the campaign by giving or attending a lecture or seminar. The "Save Your Skin" campaign is worthy of their support. Meanwhile we could all do more to find out precisely what does get on to our patients' skins at work.

R J G RYCROFT

Consultant Dermatologist,

St John's Hospital for Diseases of the Skin,

London WC2H 7B

and

Senior Employment Medical Adviser (Dermatology),

Health and Safety Executive,

London W2 4TF

1 Department of Health and Social Security. Social security statistics. London: HMSO, 1985.

2 Johnson ML, Roberts J. Prevalence of dermatological disease in the United States: a review of the National Health and Nutrition Examination Survey, 1971-1974. Am f Ind Med 1985;8:451-60. 3 Rycroft RJG. Occupational diseases among office personnel. State of the Art Reviews in Occupational Medicine 1986;1:323-8.

4 Fregert S. Occupational dermatitis in a 10-year material. Contact Dermatitis 1975;1:96-107.

\title{
Patient safety and doctors with HIV infection
}

After the recent case in which the High Court stopped the News of the World naming two doctors with the acquired immune deficiency syndrome (AIDS) the media justifiably concentrated on the risk to patients being cared for by doctors infected with the human immunodeficiency virus (HIV) (p 1339). Less justifiable was the suggestion that some doctors, and in particular the Department of Health, are engaged in a cover up to protect doctors.

Once again it is important to restate that HIV infection and AIDS are not contagious. There is no well documented evidence that the virus is spread by saliva or sputum, casual or social contact, and by sharing cups, eating and cooking utensils, toilets, and air space with an infected person. This is supported both by the facts that non-sexual family contacts of patients with the AIDS related complex or AIDS have not been infected with HIV and that health care workers in the United States caring for many people infected with HIV have not been infected casually. The only recorded cases of infection have followed needlestick injuries or mucous membrane exposure, but only $1 \%$ have seroconverted after such exposure. This illustrates that apart from sexual transmission infection has been shown to occur only if blood is deposited beneath the skin or on to mucous membranes. There are no clinical or epidemiological data to suggest that any doctors or dentists have infected one of their patients. The suggestion that this could occur is purely theoretical.

Nevertheless, this lack of evidence should not allow us to be cavalier in our approach to the possible threat of infection to patients, but our approach must be based on a rational and non-emotional assessment of risk. The risk to a patient of infection by an infected doctor must depend on what procedures are carried out by that doctor. Thus there is a theoretical risk of transmission of HIV if an infected doctor is carrying out an invasive or operative procedure and himself bleeds into his patient. The guidelines outlined by the United States Centers for Disease Control in August 1987 state: "The question of whether workers infected with HIVespecially those who perform invasive procedures-can adequately and safely be allowed to perform patient-care duties or whether their work assignments should be changed must be determined on an individual basis." The BMA has said that those carrying out invasive procedures should not continue to work where they could theoretically infect a patient. Many doctors and patients might think that given the knowledge that blood is infectious and that surgeons with hepatitis B (even though more infectious) have infected patients it would be preferable for the surgeon to cease operating. Here a lack of evidence for such events having occurred may not be sufficiently strong grounds to avoid the pragmatic decision to stop operating. Others, however, would argue that adherence to good control of infection procedures such as wearing gloves and being cautious when using sharp instruments and needles would mean that infection should not occur.

Leaving aside the theoretical possibilities of invasive procedures, sensible control of infection procedures used by doctors at large would protect all patients. Thus, gloves should be worn for any procedures that necessitate contact with the patient's body fluids. Also an infected practitioner with hand lesions such as eczema or open wounds should cover these; these procedures should be second nature to doctors. It has been suggested that the dementia associated with AIDS would put patients at risk. Again, we have 
to remind ourselves of what procedures such a doctor is carrying out and that dementia and alcoholism are, unfortunately, not new among practising doctors.

The central element of managing infected doctors and protecting their patients is to create an environment in which this management is possible. If, for example, it was considered desirable to dissuade infected surgeons from operating how would they be identified? Surely not through obligatory screening of all surgeons; this makes no more sense than screening all patients to "protect" surgeons. Total confidentiality must be preserved so that doctors can consult their colleagues if they are fearful of having become infected. Lack of confidentiality will discourage such individuals from coming forward and must be judged as detrimental to their health care. Surely the court case was about protecting the principles of confidentiality and was not an effort at a cover up. Without the certainty of confidentiality infected doctors and all other patients will not consult, and the public health will thus be compromised. If infected doctors are driven underground they will not be aware of their antibody state and thus will not be offered care, assessment, and counselling. This might lead to ignorance of their deteriorating health and performance and dementia and failure to become educated about adequate infection control procedures. Doctors with HIV infection and AIDS can be best helped by creating a non-Draconian, confidential, and sympathetic environment that encourages them to seek help. Ultimately this will be the best way for patients and doctors to be protected.

MICHAEL ADLER

Professor of Genitourinary Medicine,

University College and Middlesex School of Medicine,

James Pringle House,

Middlesex Hospital,

London WIN 8AA

\section{Regular Review}

\section{Clinical experimentation in obstetrics}

\section{R J LILFORD}

Clinical decisions should be based on well conducted clinical experiments. Control patients must be randomly chosen in order to avoid bias (inaccuracy) and measures must be taken to ensure that the important variables are equally distributed between treatment and control groups. ${ }^{1}$ Unfortunately, obstetricians have been found wanting in commitment to follow these principles. ${ }^{2}$

Following these principles in perinatal medicine is, however, particularly difficult. Enormous samples are needed to show the small changes that are hoped for in outcomes such as stillbirth, handicap, and congenital abnormality rates because most pregnancies are successful. In contrast, physicians deal mostly with chronic symptoms, where trials on one patient may be possible, ${ }^{3}$ or with conditions carrying a high mortality. Thus, though a trial with about 1000 patients in each arm is large enough to show a 5\% reduction in a common event such as death after myocardial infarction, a trial 100 times larger is needed to show the same percentage reduction in the intrapartum stillbirth rate at the same level of significance. Small trials lack power-the ability to detect a true difference-and where statistical significance is present the magnitude of the difference is likely to be exaggerated. ${ }^{45}$ The difficulty of a clinical trial in obstetrics will depend largely on the number of patients required and the ease with which they can be recruited. Some trials can realistically be mounted within a short time and carried out in a single hospital unit, others require multicentre collaboration, while in some cases the requisite population size renders the question unanswerable.

\section{Trials feasible in a single unit}

Trials that can be carried out in a single unit are usually those where the endpoint is a continuous variable or ordinal scale rather than a proportion (rate). Thus trials with fewer than 100 patients in each arm will detect a $5 \%$ drop in mean blood pressure, a 0.05 change in $\mathrm{pH}$ in fetal blood, or a gain of two weeks before delivery. (These figures are based on a power of $85 \%$, a significance level of $5 \%$, and reasonable estimates for standard deviation.) Sometimes these are important measures in themselves-for example, gestational age-but usually they are surrogate measures for other more important endpoints.

Lactic acid concentration, $\mathrm{pH}$ of fetal blood, or Apgar score at birth may be used as surrogate measures for stillbirth or asphyxial brain damage; the assumption is that any measure with a favourable effect on these variables will also favourably change certain more important endpoints. This is a dangerous extrapolation because variables such as the mean fetal blood $\mathrm{pH}$ at birth may be measurably improved by a small effect on many people while a larger, deleterious effect on a rare endpoint, such as stillbirth, will go undetected.

\section{Trials requiring larger populations}

Differences in proportions (rates) are usually much more difficult to detect. Occasionally in obstetrics we are interested in common events such as the incidence of dyspareunia after 